\title{
Network topology of stable isotope interactions in a sub-arctic raptor guild
}

Dalerum, F. 1,2,3 , Hellström, P. ${ }^{3,4}$, Miranda, M. ${ }^{5,6}$, Nyström, J. $^{3}$, Ekenstedt, J. $^{3}$, and Angerbjörn, A. ${ }^{3}$

${ }^{1}$ Research Unit of Biodiversity (UO-CSIC-PA), University of Oviedo, Mieres Campus, 33600 Mieres, Spain

${ }^{2}$ Mammal Research Institute, Department of Zoology and Entomology, University of Pretoria, Private Bag X20, 0028 Pretoria, South Africa

${ }^{3}$ Department of Zoology, Stockholm University, 106 91, Stockholm, Sweden

${ }^{4}$ Department of Environmental Research and Monitoring, Swedish Museum of Natural History, Frescativägen 40, 11418 Stockholm, Sweden

${ }^{5}$ Centre for African Ecology, School of Animal, Plant and Environmental Sciences, University of the Witwatersrand, Private Bag 3, Wits 2050, Johannesburg, South Africa ${ }^{6}$ Present address: Sports Economics Observatory Foundation (FOED), Department of Economics, University of Oviedo, 33203 Oviedo, Spain

\section{Author contributions}

FD and AA conceived the study, PH, JN and JE conducted the research, FD and MM analysed the data, FD, MM, AA and PH wrote the manuscript.

\section{Oecologia In Press}




\begin{abstract}
:
Predation is an ecologically important process, and intra-guild interactions may substantially influence the ecological effects of predator species. Despite a rapid expansion in the use of mathematical graph theory to describe trophic relations, network approaches have rarely been used to study interactions within predator assemblages. Assemblages of diurnal raptors are subject to substantial intra and interspecific competition. Here we used the novel approach of applying analyses based on network topology to species-specific data on the stable isotopes ${ }^{13} \mathrm{C}$ and ${ }^{15} \mathrm{~N}$ in feathers to evaluate patterns of relative resource utilization within a guild of diurnal raptors in northern Sweden. Our guild consisted of the golden eagle (Aquila chrysaetos), the gyrfalcon (Falco rusticolus), the peregrine falcon (Falco peregrinus) and the rough-legged buzzard (Buteo lagopus). We found a modular trophic interaction structure within the guild, but the interactions were less nested than expected by chance. These results suggest low redundancy and hence a strong ecological importance of individual species. Our data also suggested that species were less connected through intra-guild interactions than expected by chance. We interpret our results as a convergence on specific isotope niches, and that body size and different hunting behaviour may mediate competition within these niches. We finally highlight that generalist predators could be ecologically important by linking specialist predator species with disparate dietary niches.
\end{abstract}

Key words: predation, inter-specific interactions, graph theory, competition, resource partitioning 


\section{Introduction}

Predation is a key component in most ecological systems, imposing both direct and indirect effects on ecosystem properties (Taylor 1984; Terborgh et al. 1999). Interactions between functionally similar predators may influence their ecological roles (Sih et al. 1998). The ecological consequences of such interactions are determined by the relative ecological attributes of co-existing species (Dalerum et al. 2012). Therefore, the structure of predator assemblages, as well as the species interactions within such assemblages, may have pivotal influences on the overall effects of predation in any given ecosystem (Sih et al. 1998; Woodroffe and Ginsberg 2005; Dalerum 2013).

An emerging interest in community ecology has led to the adaptation of mathematical graph theory to describe trophic relations among species (Proulx et al. 2005). However, despite its applicability to predation processes, topological approaches to study trophic interactions within predator assemblages have been surprisingly neglected (Miranda et al. 2013). In an ecological context, a trophic network typically consists of two sets of discrete nodes that are connected through links representing resource use (Elton 1927), where the nodes usually represent species or other recognizable taxonomic units, although exceptions exists (e.g., Miranda et al. 2014). Characterizations of trophic network topology allow for evaluations of interspecific patterns in resource use (Sugihara 1984), where nested and modular patterns may be particularly relevant for ecosystem properties (May 1973, Bascompte et al. 2003; Newman 2006; Thébault and Fontaine 2010; Stouffer and Bascompte 2011). Nested patterns emerge when the resources used by specialist consumers are a subset of the resources used by generalist ones (Bascompte et al. 2003). In nested patterns of resource use, there is thus a large redundancy that may improve the stability of ecosystem dynamics (Holling 1973). A modular pattern is characterized by delimited sub-communities of consumers and resources, with more frequent and stronger interactions between organisms within than between sub-communities (May 1973; Prado and Lewinsohn 2004). Modular patterns may be ecologically important by delimiting the impacts of perturbations to specific modules, so that they may not permeate through the entire ecosystem (Stouffer and Bascompte 2011).

However, much of our theoretical understanding of network topology comes from networks that quantify interactions among only one set of nodes, i.e. unipartite networks. It may therefore be fruitful to also re-project bipartite networks into unipartite ones (Newman 2001; Opsahl 2009), which then will link species on the same trophic level through interactions quantified from shared resources (Padrón et al. 2011). Unipartite projections of trophic interactions can hold useful information regarding intraguild processes, such as competition and facilitation among species (Miranda et al. 2013), as well as ecosystem properties of consumer guilds (Dunne et al. 2002; Jordán 2009). They may also aid in identifying ecologically important species (Jordán et al. 2006) and to identify species most likely to be influenced by ecosystem perturbations such as biological invasions (Carvalheiro et al. 2008). The relative importance of individual species can be quantified through centrality indices, which for trophic networks describe the number of other species with which a species share resources (Estrada 2007).

Analysis of naturally occurring stable isotopes has become well established as a tool for investigating consumer resource use (Dalerum and Angerbjörn 2005; Martínez del Rio et al. 2009). However, topological approaches have rarely been applied to stable isotope data (but see Miranda et al. 2014). This is unfortunate, because isotope data contain information 
about resources assimilated over time. They can therefore provide supplementary information to more direct methods of resource use, and hence provide a more complete evaluation of the resource use among and within consumer assemblages.

Raptor assemblages are subject to substantial intra and interspecific competition, where local environmental factors often determine the importance of competition in any given raptor community (Jaksić and Braker 1983). Raptors can have significant ecological effects and function as efficient umbrella species for biodiversity conservation (Sergio et al. 2006). In this study, we used stable isotopes of carbon and nitrogen in the feathers of four species of diurnal raptors in northern Sweden, the golden eagle (Aquila chrysaetos), the rough-legged buzzard (Buteo lagopus), the gyrfalcon (Falco rusticolus), and the peregrine falcon (Falco peregrinus), to evaluate patterns of relative resource utilization within and among these sympatric predators in a sub-arctic environment. In particular, we used topological approaches to identify if there was any evidence for nested and compartmental community structures, and to evaluate if the patterns of intra-guild interactions suggested inter or intra-specific competition or facilitation.

\section{Methods}

Study area and sample collection

Feather samples were collected while conducting routine monitoring of 39 golden eagle nests, 14 rough-legged buzzard nests, 13 gyrfalcon nests, and 3 peregrine falcon nests. All nests were in the foothills of the Fennoscandian mountain range in the two northernmost counties in Sweden (Norrbotten and Västerbotten). We collected a total of 111 moulted flight feathers, 37 form adult and 26 from juvenile golden eagles, 12 from adult and 8 from juvenile rough legged-buzzards, 19 from juvenile gyrfalcons and 9 from juvenile peregrine falcons. The nests were visited during June and July (Nyström et al. 2005; Nyström et al. 2006; Hellström et al. 2014). Hence, the isotope values in feathers from juvenile birds reflect the diet of the current spring and summer. Moulting patterns in adult raptors is varied, with both eagles and buzzards showing serial moult, were a section of the primaries are at any given time, whereas large falcons tends to replace most flight feathers annually (Edelstam 1984). Regardless of moult pattern, however, moult in all four species is generally carried out during spring - early autumn, and the growth period for a single quill is 1-2 months (Jollie 1947; Edelstam 1984; Clark 1999). Therefore, the feathers from adult birds likely reflect the diet of spring and summer from one (the two falcon species) to up to three (golden eagle and buzzard) years prior to the year of collection. Samples were collected in 1998 - 2003 for golden eagles, 2004 for rough-legged buzzards, 2002 and 2003 for gyrfalcons, and 2003 for peregrine falcons. Temporal variation between years of collection did not influence the relative differences in isotope values among the raptor species (Manova, $F_{2,98}=0.06, P=0.19$ ). In addition to the raptor feathers, we compiled available data on isotope values from potential prey species (Table 1). These are not reported as a comprehensive range of potential prey or a detailed account of the available isotope niches, but are presented to illustrate the isotope variation that caused the observed interaction patterns.

The Fennoscandian mountain range in northern Sweden is characterized by tree-less or willow-based sub-arctic mountain tundra above approximately $800 \mathrm{~m}$ altitude, and boreal forest dominated by Scots pine (Pinus silvestris) and Norway spruce (Picea abies) at lower altitudes. Key food sources for raptors are carrion of moose (Alces alces) and semi- 
domesticated reindeer (Rangifer tarandus), as well as potential prey species such as mountain hares (Lepus timidus), Norwegian lemming (Lemmus lemmus), microtine rodents (Microtus agrestis, Myodus rufocanus, and Myodes glareolus), two species of grouse (Lagopus lagopus and Lagopus muta), and various species of migratory birds.

\section{Sample treatment and stable isotope analyses}

We rinsed feathers by sonicating them in a chloroform/methanol/water (1:2:1) solution to remove surface attached lipids and contaminants, and after air drying we clipped $0.1-0.8$ g into tin capsules for analyses. We analyzed ${ }^{13} \mathrm{C} /{ }^{12} \mathrm{C}$ and ${ }^{15} \mathrm{~N} /{ }^{14} \mathrm{~N}$ ratios on a Carlo Erba elemental analyzer (E1108 CHNS-O) connected to a Fison Optima isotope ratio mass spectrometer, with a standard deviation of $<0.1 \%$. Isotope values are presented as $\mathrm{dX}$ values, which represent the proportional deviation in parts per thousand (\%o) from a standard: $\mathrm{X}=1000 \times\left(\mathrm{R}_{\text {sample }} / \mathrm{R}_{\text {standard }}\right)-1$, where $\mathrm{X}$ is either $\delta^{13} \mathrm{C}$ or $\delta^{15} \mathrm{~N}$ and $\mathrm{R}$ is either $13 \mathrm{C} / 12 \mathrm{C}$ or $15 \mathrm{~N} / 14 \mathrm{~N}$, respectively. The accepted standard for carbon is Pee Dee Belemnite (PDB) and the standard for nitrogen is air.

\section{Data analyses}

To describe the structure of isotope relationships between the different study species and age classes, we adapted network tools derived from graph theory (Miranda et al. 2013). We conducted our analyses on separate age classes partly since certain prey may have been favoured to bring back to the nests (e.g., Lindström 1994; Catry et al. 2016), and partly because the isotopes in adult and juvenile feather reflected different time periods. We first generated a bipartite network for each element, in which the consumer nodes represented the species and age class categories and the resource nodes a categorized representation of respective $\delta^{13} \mathrm{C}$ and $\delta^{15} \mathrm{~N}$ values (Miranda et al. 2014). We set all isotope categories within each element to be of equal width. We defined the isotope width of each isotope category as the average standard deviation of isotope values within species and age class groups, which was 0.4 for $\delta^{13} \mathrm{C}$ and 0.78 for $\delta^{15} \mathrm{~N}$. We weighted the networks by the number of individuals that contributed to a specific isotope class. Secondly, we projected the weighted bipartite networks into weighted unipartite networks to further describe the structure of interactions between the different consumer groups. In these projected networks, shared utilization of an isotope category between two consumer groups was represented as a link, which was weighted according to the number of individuals that contributed to the link (i.e. shared the isotope category with another group). We used raw isotope data without attempting to correct for isotopic fractionation in the analyses (Table $1)$.

We used the QuaBiMo algorithm to determine the degree of modularity (Q) in the bipartite networks (Dormann and Strauss, 2013). This algorithm adapts a simulated annealingMonte Carlo procedure to identify the best aggregation of links into modules (Danon et al. 2005). Following Dormann and Strauss (2013), we set the number of swaps to $10^{6}$. The modularity index $\mathrm{Q}$ ranges from 0 , indicating that links within modules are not higher than expected by chance, to a maximum value of 1 when modules are completely discretely delimited. We have presented the identified modules in interaction matrices, which provide a visual representation of the identified modules (Dormann and Strauss 2013).

We used the weighted-interaction nestedness (WIN) index to quantify the degree of nestedness in the bipartite networks (Galeano et al. 2008). This value is calculated by 
ordering the rows of the interaction matrix from top to bottom and columns from left to right, in ascending order according to the number of links. The WIN is then calculated as the mean weighted Manhattan distance from each of the matrix cells containing a link to the cell corresponding to the intersection of the row and columns with the lowest link number (see Galeano et al. 2008 for detailed descriptions of calculations). For ease of interpretation, however, we have presented the nestedness values as the weighted nestedness estimator (WINE), which ranges from 0 which represents a completely random interaction structure to 1, which represents a maximally nested structure (Galeano et al. 2008).

In the unipartite projections, we calculated a weighted degree centrality index for each species and age class (Freeman 1979). This index quantified the number of other species and age classes that shared isotope values weighted by the number of individuals contributing to each link. This value thus describes how many other raptor groups each group share its isotope values with. We opted for this local index since our network was very small. Therefore, other centrality indices that better quantify centrality through indirect links between regions in larger networks were not directly relevant (Jordán et al. 2006). In addition to calculating degree centrality for each of the species and age-class groups, we also calculated the average degree centrality across species and age classes as a representation of the degree of centrality in each unipartite network. Such network scale metrics can provide information of the relative patterns of resource partitioning within consumer guilds.

To evaluate if the values of modularity, nestedness and centrality deviated from random expectations, we compared the observed values to those obtained from 1000 random matrices. The random matrices were constrained to retain marginal totals (abundances) from the original matrix, to control for unequal numbers of sampled animals across species and age classes. Each random bipartite matrix was also projected into a unipartite matrix, to enable comparisons of centrality measure to random expectations. We converted each observed metric to a z-score by subtracting the mean and dividing by the standard deviation of each respective random distribution, to allow for a formal evaluation of departure from random expectations in each observed index value. To enable comparisons between metrics derived for $\delta^{13} \mathrm{C}$ and $\delta^{15} \mathrm{~N}$, we subtracted the values calculated from the random matrices from each observed value (Manly 1997), and used these deviations from random expectations to compare compartmentalization, nestedness and centrality between the $\delta^{13} \mathrm{C}$ and $\delta^{15} \mathrm{~N}$ networks using two sample permutation tests.

Statistical analyses were conducted in the package R version 2.15.1 for Mac and Linux (http://www.r-project.org) using the user contributed packages bipartite (Dormann et al. 2008), coin (Hothorn et al. 2008) and network (Butts 2008).

\section{Results}

The interaction patterns of both the $\delta^{13} \mathrm{C}$ and $\delta^{15} \mathrm{~N}$ bipartite networks were less nested but more modular than random expectations (Table 2). The $\delta^{13} \mathrm{C}$ interaction patterns had both lower degree of modularity $(Z=-39.27, P<0.001)$ and were less nested $(Z=-18.65, P<$ 0.001 ) than the $\delta^{15} \mathrm{~N}$ interactions (Fig. 1a,b). For $\delta^{13} \mathrm{C}$, adult and juvenile rough-legged buzzards formed a module containing values relatively depleted in ${ }^{13} \mathrm{C}$, adult and juvenile golden eagles formed a module together with juvenile peregrine falcons containing intermediate $\delta^{13} \mathrm{C}$ values, and gyrfalcons formed an isolated module containing values 
relatively enriched in ${ }^{13} \mathrm{C}$ (Fig. 1c). For $\delta^{15} \mathrm{~N}$, adult golden eagles and juvenile peregrine falcons formed a module containing values relatively enriched in ${ }^{15} \mathrm{~N}$, juvenile golden eagles formed a module together with adult and juvenile rough-legged buzzards containing intermediate $\delta^{15} \mathrm{~N}$ values, and gyrfalcon again formed an isolated module containing values relatively depleted in ${ }^{15} \mathrm{~N}$ (Fig. 1d).

The unipartite projections of both the $\delta^{13} \mathrm{C}$ and $\delta^{15} \mathrm{~N}$ bipartite relationships showed less degree centrality than random expectations (Fig. 2a,b, Table 2), but the $\delta^{13} \mathrm{C}$ interactions showed higher degree centrality than the $\delta^{15} \mathrm{~N}$ ones $(Z=20.37, P<0.001)$. Similar patterns were found for all the species, which had lower degree centrality than random expectations (Table 2) and consistently higher degree centrality for $\delta^{13} \mathrm{C}$ than for $\delta^{15} \mathrm{~N}$ interactions (adult golden eagle: $Z=35.70, P<0.001$; juvenile golden eagle: $Z=35.92, P<0.001$; adult rough legged buzzard: $Z=9.67, P<0.001$, juvenile rough-legged buzzard: $Z=23.31$, $P<0.001$; juvenile gyrfalcon $Z=6.96, P<0.001$, juvenile peregrine falcon $Z=34.22, P<$ $0.001)$. For both the $\delta^{13} \mathrm{C}$ and the $\delta^{15} \mathrm{~N}$ interactions, golden eagles had the highest degree centrality (Table 2) and gyrfalcon and peregrine falcon shared few isotope values with the other species, particularly for $\delta^{15} \mathrm{~N}$ (Fig. 2b).

\section{Discussion}

We observed significant modular structures of the isotope interactions within the raptor guild, and we similarly observed less nested isotope interaction patterns than random expectations. Modular structures have previously been linked to an increased stability of the ecosystem process of concern, because any effects of perturbations likely will be restricted within isolated modules (Prado and Lewinsohn 2004; Stouffer and Bascompte 2011). However, the lack of nested patterns suggests little redundancy across modules. Such lack of redundancy has previously been suggested for top predators (Woodroffe and Ginsberg 2005), and highlights that any ecosystem effects of raptor predation in the subarctic areas of northern Sweden may be fragile and that the loss of individual species may highly influence ecosystem dynamics.

If re-projected into unipartite graphs, interactions quantified both through $\delta^{13} \mathrm{C}$ and through $\delta^{15} \mathrm{~N}$ yielded networks with lower degree centrality than expected by chance. These results imply that the raptor species were separated in their isotope values more than what would have been the case if they had randomly distributed across carbon and nitrogen isotope space. We suggest that these observed patterns may reflect competition-mediated resource partitioning (sensu Schoener 1974). Of the four species, the golden eagle was the most connected, both in terms of interactions through $\delta^{13} \mathrm{C}$ and $\delta^{15} \mathrm{~N}$. This result agrees with the relative predation strategies between the four species, where golden eagles have a much broader dietary niche (e.g., Tjernberg 1981; Nyström et al. 2006) compared to both roughlegged buzzards (Hellström et al. 2014) and the two falcon species (Mearns 1983;

Rosenfield et al. 1995; Nyström et al. 2005). We suggest that these results points to a potential role for generalist predators to function as ecological links between specialist predators with disparate diets. Such ecological homogenization could have important consequences for both predator and prey populations, and we highlight that while specialist predators may be ecologically important by directly influencing their prey populations (Anderson and Erlinge 1977), the ecological effects of generalist predators may partly be related to indirect effects caused by linking otherwise un-connected ecological components (Abrams 1983; Martín-González et al. 2009). 
For our raptor guild, we suggest that the modular patterns reflect substantial dietary overlap within modules (e.g., between rough-legged buzzards and golden eagles and between golden eagles and peregrine falcons), but that the low centrality values nevertheless suggest a significant competition-mediated resource partitioning. We suggest that the substantial size differences, as well as differences in hunting behaviour, may sustain these modular structures in the face of potential inter-specific competition (Brown and Wilson 1956). For both the $\delta^{13} \mathrm{C}$ and the $\delta^{15} \mathrm{~N}$, gyrfalcon formed a separate module, which illustrates the contrasting predator strategies of this species, which almost exclusively prey on ptarmigan (Nyström et al. 2005).

We found lower structuring of interactions in $\delta^{13} \mathrm{C}$ compared to $\delta^{15} \mathrm{~N}$ networks. In terrestrial ecosystems, variation in $\delta^{13} \mathrm{C}$ is usually mediated by contrasts between plants with $\mathrm{C} 3$ and $\mathrm{C} 4$ photosynthesis, and by input from marine vs. terrestrial carbon, whereas variation in $\delta^{15} \mathrm{~N}$ is more complex (Peterson and Fry 1987). In northern Sweden, terrestrial ecosystems are largely dominated by plants of the $\mathrm{C} 3$ photosynthetic pathway (Still and Berry 2003), and the low $\delta^{13} \mathrm{C}$ in the raptor feathers points to a limited influence of prey that are connected to marine resources (e.g., Chisholm et al. 1982). We suggest that our observation of higher structuring in $\delta^{15} \mathrm{~N}$ is a reflection of properties of the terrestrial origin of the food chains, of which raptors are a part, where processes such a nitrogen fixation and the trophic position of prey may influence the relative isotope niches exhibited by the individual species

To conclude, our approach to analyse stable isotope data using network topology suggested a compartmentalized trophic interaction structure among large Swedish raptors, but we found that species were less connected through intra-guild interactions than suggested by chance. We interpret these results as an indication of convergence on specific isotope niches, and that body size and different hunting behaviour mediates competition within these niches. We further found no nested interaction structures, suggesting low redundancy and a potentially high ecological importance of individual species. Finally, we found that the most generalist species had the highest centrality value, which exemplifies that generalist predators may be critically important by linking otherwise separated ecological components.

\section{References}

Abrams P (1983) Arguments in favour of higher order interactions. Am Nat 121:887-891

Anderson M, Erlinge S (1977) Influence of predation on rodent populations. Oikos 29:591597

Bascompte J, Jordano P, Melian CJ, Olesen JM (2003) The nested assembly of plantanimal mutualistic networks. Proc Nat Acad USA 100:9383-9387

Brown WL, Wilson EO (1956) Character displacement. Syst Zool 5:49-64

Butts C (2008) Network: a Package for Managing Relational Data in R. J Stat Softw 24:2

Carvalheiro LG, Barbosa ERM, Memmott J (2008) Pollinator networks, alien species and the conservation of rare plants: Trinia glauca as a case study. J Appl Ecol 45:14191427.

Catry I, Catry T, Alho M, Franco AMA, Moreira F (2016)Sexual and parent-offspring dietary segregation in a colonial raptor as revealed by stable isotopes. J Zool Lond Early view doi:10.1111/jzo.12324

Chisholm BS, Nelson DE, Schwartcz HP (1982) Stable carbon isotope ratios as a measure of marine versus terrestrial protein in ancient diets. Science 216:1131-1132

Clark WS (1999) A field guide to the raptors of Europe, the Middle East, and North Africa. 
Oxford:Oxford University Press.

Dalerum F (2013) Phylogenetic and functional diversity in large carnivore assemblages. Proc Roy Soc B 280:20130049

Dalerum F, Angerbjörn A (2005) Resolving temporal variation in vertebrate diets using naturally occurring stable isotopes. Oecologia 144:647-658

Dalerum F, Cameron EZ, Kunkel KE, Somers MJ (2012) Interactive effects of species richness and species traits on functional diversity and redundancy. Theor Ecol 5:129139

Danon L, Diaz-Guilera A, Duch J, Arenas A (2005) Comparing community structure identification. J Stat Mech Theor Exp P09008

Dormann CF, Gruber B, Fruend J (2008) Introducing the bipartite package: Analysing ecological networks. R news 8:8-11

Dormann CF, Strauss R (2013) Detecting modules in quantitative bipartite networks: the QuaBiMo algorithm. arXiv1304.3218

Dunne J, Williams RJ, Martinez ND (2002) Network structure and biodiversity loss in food webs: robustness increases with connectance. Ecol Lett 5:558-267

Edelstam C (1984) Patterns of moult in large birds of prey. Act Zool Fenn 21:271-276

Ehrich D, Tarroux A, Stien J, Lecomte N, Killengreen S, Berteaux D, Yoccoz NG (2011) Stable isotope analysis: modelling lipid normalization for muscle and eggs from arctic mammals and birds. Meth Ecol Evol 2:66-76

Elton CS (1927) Animal ecology. Sidgwick and Jackson, London

Estrada E (2007) Characterization of topological keystone species local, global, and 'meso-sale' centralities in food webs. Ecol Compl 4:48-57

Freeman LC (1979) Centrality in social networks: Conceptual clarification. Soc Netw $1: 215-239$

Fox AD, Hobson KA, Kahlert J (2009) Isotopic evidence for endogenous protein contributions to greylag goose Anser anser flight feathers. J Avian Biol 40:108:112

Galeano J, Pastor JM, Iriondo JM (2008) Weighted-Interaction Nestedness Estimator (WINE): a new estimator to calculate over frequency matrices. arXiv $0808.3397 \mathrm{v} 1$

Hellström P, Nyström J, Angerbjörn A (2014) Functional responses of the rough-legged buzzard in a multi-prey system. Oecologia 174:1241-1254

Holling CS (1973) Resilience and stability of ecological systems. Ann Rev Ecol Syst 4:123

Hothorn T, Hornik M, van der Wiel MA (2008) Implementing a class of permutation tests: The coin package. J Stat Softw 28:1-23

Jaksić FM, Braker HE (1983) Food-niche relationships and guild structure of diurnal birds of prey: competition versus opportunism. Can J Zool 61:2230-2241

Jollie M (1947) Plumage changes in the golden eagle. Auk 64:549-576

Jordán F (2009) Keystone species and food webs. Phil Tr Roy Soc B 364:1733-1741

Jordán F, Wei-chung L, Davis AJ (2006) Topological keystone species: measures of topological importance in food webs. Oikos 112:535-546

Lindström E (1994) Large prey for small cubs - on crucial resources of a boreal red fox population. Ecography 17:17-22

Manly BFJ (1997) Randomization, bootstrap, and Monte Carlo methods in biology. 2nd ed. Chapman and Hall, London

Martín-González AM., Dalsgaard B, Olesen JM (2010) Centrality measures and the importance of generalist species in pollination networks. Ecol Compl 7:36-43

Martínez del Rio C, Wolf N, Carleton SA, Gannes LZ (2009) Isotopic ecology ten years after a call for more laboratory experiments. Biol Rev 84:91-111 
Mearns RJ (1983) The diet of the Peregrine Falco peregrinus in south Scotland during the breeding season. Bird Study 30:81-90

May RM (1973) Stability and complexity in model ecosystems. Princeton University Press, Princeton

Miranda M, Parrini F, Dalerum F (2013) A categorization of network approaches to analyse trophic relationships. Meth Ecol Evol 4:897-905

Miranda M, Dalerum F, Parrini F (2014) Interaction patterns within a multi-herbivore assemblage derived from stable isotopes. Ecol Comp 20:51-60

Newman MEJ (2001) Scientific collaboration networks. II. Shortest paths, weighted networks, and centrality. Phys Rev E 64:016132

Newman MEJ (2006) Modularity and community structure in networks. Proc Nat Acad Sci USA 113:8577-8582

Nyström J, Ekenstedt J, Angerbjörn A, Thulin L, Hellström P, Dalen L (2006) Golden eagles on the Swedish mountain tundra - diet and breeding success in relation to prey fluctuations. Orn Fenn 83:145-152

Nyström J, Ekenstedt J, Engström J, Angerbjörn A (2005) Gyr falcons, ptarmigan and microtine rodents in northern Sweden. Ibis 147:587-597

Opsahl T (2009) Projecting two-mode networks onto weighted one-mode networks. http://toreopsahl.com/2009/05/01/projecting-two-mode-networks-onto-weightedone-mode-networks.

Padrón B, Nogales M, Traveset A (2011) Alternative approaches of transforming bimodal into unimodal mutualistic networks. The usefulness of preserving weighted information. Bas Appl Ecol 12:713-721

Peterson BJ, Fry B (1987) Stable isotopes in ecosystem studies. Ann Rev Ecol Syst 18:293-320

Prado PI, Lewinsohn TM (2004) Compartments in insect-plant associations and their consequences for community structure. J Anim Ecol 73:1168-1178

Proulx SR, Promislow DEL, Phillips PC (2005). Network thinking in ecology and evolution. Tr Ecol Evol 20:345-353

Reitan M (2013) Assessing the diet of the golden eagle (Aquila chrysaetos) and the biomagnification of metals by use of stable isotope analyses and ICP-MS. MSc thesis, Department of Biology, Norwegian University of Science and Technology, Trondheim, Norway

Rosenfield RN, Schneider JW, Papp JM, Seegar WS (1995) Prey of peregrine falcons breeding in west Greenland. Condor 3:763-770

Schoener TW (1974) Resource partitioning in ecological communities. Science 185:27-39

Sergio F, Newton I, Marchesi L, Pedrini P (2006) Ecologically justified charisma: preservation of top predators delivers biodiversity conservation. J Anim Ecol 43:1049-1055

Sih A, Englund G, Wooster D (1998) Emergent impacts on multiple predators on prey. $\mathrm{Tr}$ Ecol Evol 13:350-355

Sugihara G (1984) Graph theory, homology and food webs. Am Math Soc 30: 83-101

Still CJ, Berry JA (2003) Global distribution of $\mathrm{C}_{3}$ and $\mathrm{C}_{4}$ vegetation: Carbon cycle implications. Glob Biogeochem Cycl 17:1006

Stouffer DB, Bascompte J (2011) Compartmentalization increases food-web persistence. Proc Natl Acad USA 108:3648-3652

Szymanski ML, Afton AD, Hobson KA (2010) Use of stable isotope methodology to determine natal origins of mallards at a fine scale within the upper Midwest. J Wildl Manage 71:1317-1324

Taylor RJ (1984) Predation. Springer, New York 
Terborgh J, Estes J, Paquet P, Ralls K, Boyd-Heger D, Miller BJ, Noww RF (1999) The role of top carnivores in regulating terrestrial ecosystems. In: Soule ME, Terborgh J (eds) Continental conservation: Scientific foundations for regional reserve networks. Island Press, Washington DC, pp 39-64

Thébault E, Fontaine C (2010) Stability of ecological communities and the architecture of mutualistic and trophic networks. Science 329:853-856

Tjernberg M (1981) Diet of the golden eagle Aquila chrysaetos during the breeding season in Sweden. Holarct Ecol 4:12-19

Urton EJM, Hobson KA (2005) Intrapopulation variation in grey wolf isotope $\left(\delta^{15} \mathrm{~N}\right.$ and $\left.\delta^{13} \mathrm{C}\right)$ profiles: implication for the ecology of individuals. Oecologia 145:317-326

Weiser EL, Powell AN (2011) Evaluating gull diets: a comparison of conventional methods and stable isotope analysis. J Field Ornithol 82:297-310

Woodroffe R, Ginsberg JR (2005) King of the beast: evidence for guild redundancy among large mammalian carnivores. In: Ray J, Redford KH, Steneck R, Berger J (eds) Large carnivores and the conservation of biodiversity. Island Press, Washington DC, pp 154-176 
Table 1. Raw isotope data from feathers of northern Swedish raptors as well as representative values of $\delta^{13} \mathrm{C}$ and $\delta^{15} \mathrm{~N}$ for potential prey items.

\begin{tabular}{|c|c|c|c|c|c|c|}
\hline Common name & Latin name & $\mathrm{n}$ & $\mathrm{C}$ & $\mathrm{N}$ & Area & Reference \\
\hline Golden eagle, ad & Aquila chrysaetos & 37 & $-22.5 \pm 0.55$ & $7.80 \pm 0.73$ & Northern Sweden & This study \\
\hline Golden eagle, juv & Aquila chrysaetos & 26 & $-22.6 \pm 0.55$ & $5.06 \pm 1.13$ & Northern Sweden & This study \\
\hline Rough-legged buzzard, ad & Buteo lagopus & 12 & $-23.2 \pm 0.48$ & $5.91 \pm 0.89$ & Northern Sweden & This study \\
\hline Rough-legged buzzard, juv & Buteo lagopus & 8 & $-23.8 \pm 0.15$ & $3.52 \pm 1.02$ & Northern Sweden & This study \\
\hline Peregrine falcon, juv & Falco peregrinus & 9 & $-22.7 \pm 0.29$ & $8.12 \pm 0.49$ & Northern Sweden & This study \\
\hline Gyrfalcon, juv & Falco rusticolus & 19 & $-21.4 \pm 0.36$ & $3.52 \pm 1.02$ & Northern Sweden & This study \\
\hline \multicolumn{7}{|l|}{ Prey reference values ${ }^{\mathrm{a}}$} \\
\hline Moose & Alces alces & 59 & $-24.7 \pm 0.51$ & $1.05 \pm 0.79$ & Alaska & Adams et al. 2010 \\
\hline Moose & Alces alces & 7 & $-25.6 \pm 0.5$ & $3.1 \pm 0.83$ & Saskatchewan & Urton and Hobson 2005 \\
\hline Reindeer & Rangufer tarandus & 21 & $-22.22 \pm 0.17$ & $2.67 \pm 0.51$ & Central Norway & Reitan 2013 \\
\hline Mountian hare & Lepus timidus & 22 & $-26.09 \pm 0.94$ & $3.21 \pm 1.31$ & Central Norway & Reitan 2013 \\
\hline Scandinavian lemming & Lemmus lemmus & 5 & $-29.0 \pm 1.3$ & $1.4 \pm 1.0$ & Varanger peninsula & Ehrich et al. 2011 \\
\hline Grey-sided vole & Myodes rufocanus & 4 & $-27.2 \pm 11$ & $0.3 \pm 1.7$ & Varanger peninsula & Ehrich et al. 2011 \\
\hline Galliformes & $\begin{array}{l}\text { Lagopus lagopus } \\
\text { Tetrao urogallus }\end{array}$ & 22 & $-23.77 \pm 0.57$ & $0.61 \pm 0.88$ & Central Norway & Reitan 2013 \\
\hline Small passerines & $\begin{array}{l}\text { Calcarius lapponicus, } \\
\text { Plectrophenax nivalis, } \\
\text { Carduelis flammea }\end{array}$ & 3 & $-26.1 \pm 0.8$ & $5.1 \pm 1.9$ & Alaska & Weiser and Powell 2011 \\
\hline Greylag goose & Anser anser & 12 & $-26.4 \pm 0.35$ & $8.35 \pm 0.55$ & Denmark & Fox et al. 2009 \\
\hline Mallard & Anas platyrhynchos & 102 & $-23.3 \pm 3.64$ & $9.47 \pm 2.59$ & Central USA & Szymanski et al. 2010 \\
\hline Shorebirds & $\begin{array}{l}\text { Phalaropus lobatus, } \\
\text { Pluvialis dominica }\end{array}$ & 2 & $-28.1 \pm 2.1$ & $7.4 \pm 0.7$ & Alaska & Weiser and Powell 2011 \\
\hline
\end{tabular}

${ }^{a}$ Prey reference values are from muscle tissue except for Greylag goose, which values are from flight feathers. 
Table 2. Observed values of compartmentalization, nestedness, and degree centrality in bipartite (compartmentalization and nestedness) and unipartite (degree centrality) network representations of $\delta^{13} \mathrm{C}$ and $\delta^{15} \mathrm{~N}$ in feathers from juvenile and adult feathers from golden eagle (GE), rough-legged buzzard (RLB), gyrfalcon(GF) and peregrine falcon (PF), as well as z-scores calculated from 1000 random matrices and associated $\mathrm{p}$-values. The network values for centrality were calculated as the average of the individual species values

\begin{tabular}{|c|c|c|c|c|c|c|}
\hline & \multicolumn{3}{|c|}{$\underline{\delta^{13} \mathrm{C}}$} & \multicolumn{3}{|c|}{$\delta^{15} \mathrm{~N}$} \\
\hline & $\begin{array}{l}\text { Observed } \\
\text { value }\end{array}$ & Z-score & $\mathrm{p}$ & $\begin{array}{l}\text { Observed } \\
\text { value }\end{array}$ & Z-score & $\mathrm{p}$ \\
\hline Modularity & 0.38 & 9.20 & $<0.001$ & 0.49 & 12.83 & $<0.001$ \\
\hline Nestedness & 0.04 & -1.97 & 0.024 & $-3.86 \times 10^{-4}$ & -3.34 & $<0.001$ \\
\hline Degree centrality & 52.50 & -6.61 & $<0.001$ & 38 & -8.84 & $<0.001$ \\
\hline Juvenile GE & 81 & -3.57 & $<0.001$ & 56 & -5.98 & $<0.001$ \\
\hline Adult GE & 116 & -3.67 & $<0.001$ & 82 & -6.01 & $<0.001$ \\
\hline Juvenile RLB & 24 & -3.87 & $<0.001$ & 19 & -3.88 & $<0.001$ \\
\hline Adult RLB & 37 & -4.31 & $<0.001$ & 33 & -4.55 & $<0.001$ \\
\hline Juvenile GF & 27 & -10.22 & $<0.001$ & 21 & -9.18 & $<0.001$ \\
\hline Juvenile PF & 30 & -3.16 & $<0.001$ & 21 & -5.01 & $<0.001$ \\
\hline
\end{tabular}


a)

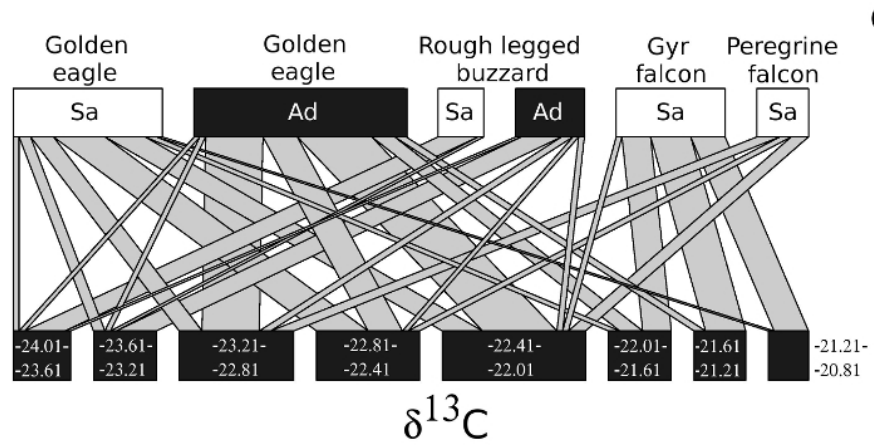

b)

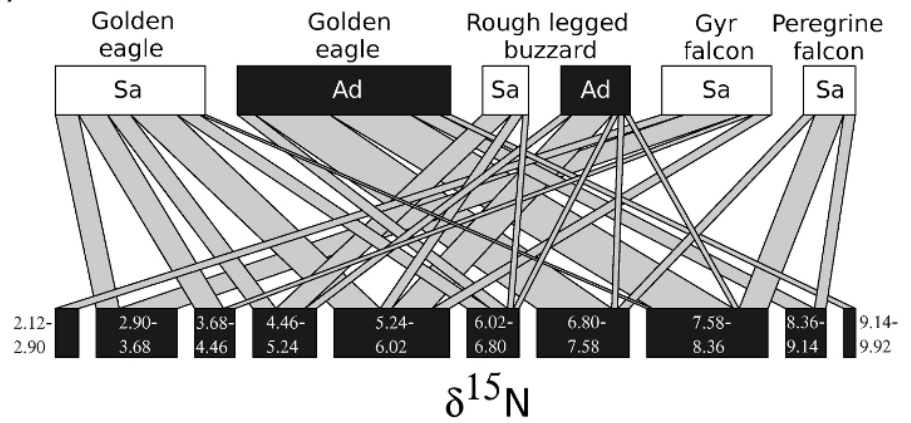

c)

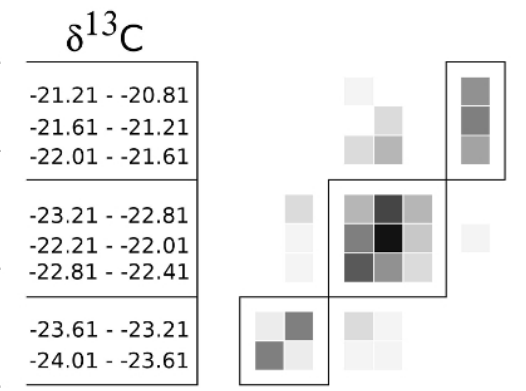

d)
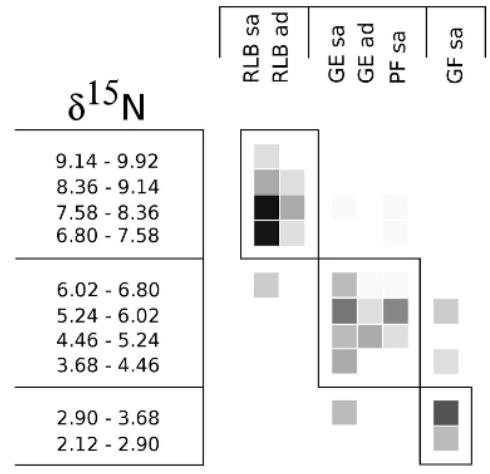

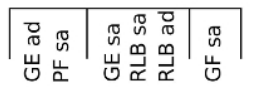

Figure 1. Bipartite network representations of the isotope composition in feathers of adult and juvenile golden eagles and rough-legged buzzards, and juvenile gyrfalcons and peregrine falcons for a) $\delta 13 \mathrm{C}$ and b) $\delta 15 \mathrm{~N}$, as well as raptor isotope interaction matrices for c) $\delta 13 \mathrm{C}$ and d) $\delta 15 \mathrm{~N}$. The width of the isotope categories was determined as the average standard deviation of the species-specific standard deviations for each isotope. The width of each link in the bipartite graphs reflects relative interaction frequency, i.e. the number of individuals it contains. The interaction matrices delineates modules found in the bipartite networks, and are coded so that darker cell values indicate higher numbers of interactions. 
a)

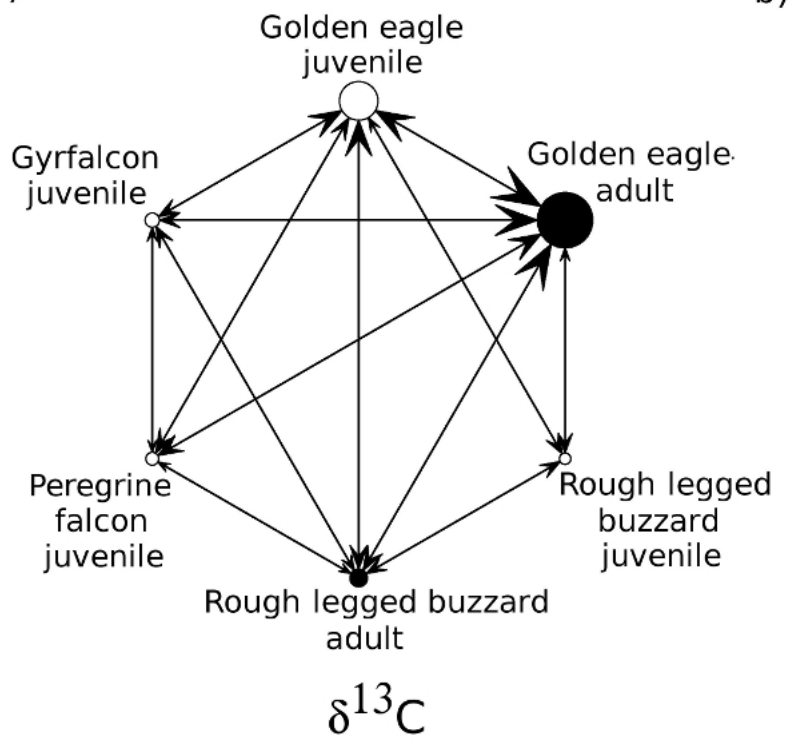

b)

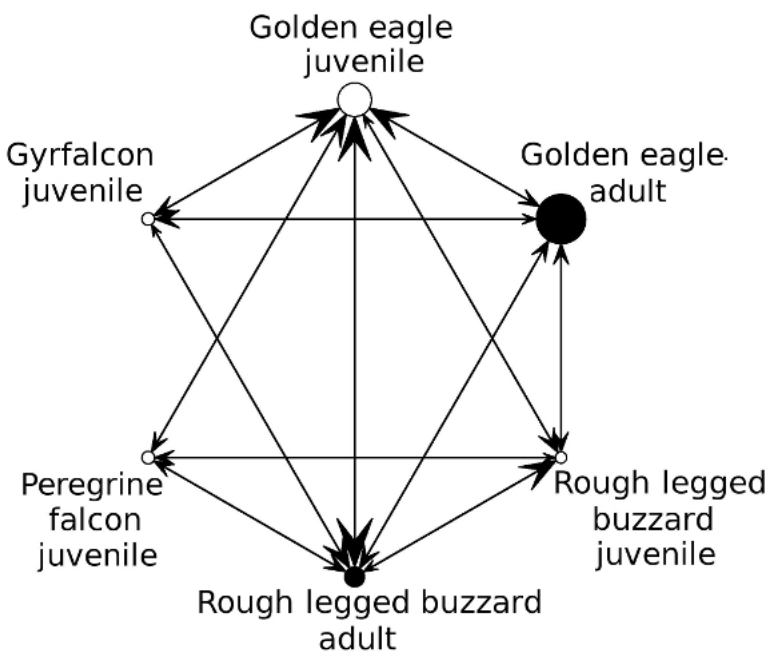

$\delta^{15} \mathrm{~N}$

Figure 2. Unipartite projections of bipartite raptor - isotope networks, describing the relationships between species and age classes by their respective $\delta^{13} \mathrm{C}$ (a) and $\delta^{15} \mathrm{~N}(\mathrm{~b})$ values. Each node represents a raptor species and age class, and each line represents the occurrence of a shared range of isotope values between two nodes. Node sizes are coded by the relative degree centrality, which describes the weighted number of connections for a specific node, and hence how connected that specific species and age class is in each isotope network. The arrows are coded by the proportion of incoming links to each specific node, and hence provide information on which other species and age classes that each node shares its isotope values with. 